\title{
O ESPORTE DA/NA ESCOLA NAS POLIITICAS PÚBLICAS EM SANTA CATARINA
}

DOI: $105902 / 0102830821707$

Data de submissão: 05-04-2016

Data de Aceite: 18-07-2016

Universidade Federal de Santa Catarina juliano_silveira@yahoo.com.br

Resumo: Esta pesquisa é fruto de uma análise documental acerca das políticas públicas para o esporte escolar em Santa Catarina. Especificamente a Proposta Curricular de Santa Catarina e o Programa Estadual Esporte Escolar. A partir da análise realizada veremos que as contradições entre os documentos são enormes, estabelecendo um conflito entre os mesmos. Assim, mostraremos o quanto podem ser diferentes as políticas para o esporte escolar dentro e fora das aulas de Educação Física e as consequências do trato com o esporte em perspectivas aparentemente tão distintas numa mesma instituição.

Palavras-chave: esporte, escola, políticas públicas. 


\section{Introdução}

Há um consenso nos estudos da área de Educação Física de que o esporte institucionalizado, como manifestação cultural inerente ao modo de produção social vigente, incorpora as características predominantes no processo de produção capitalista, tal como o alto rendimento, a exclusão, a sobrepujança, as comparações objetivas, competição exacerbada, etc (BRACHT, 2003; KUNZ, 2001). E, consequentemente, além de forjar uma instituição voltada para a produtividade, a disciplina, a eficiência e o controle, marcando de forma determinante a maneira como os sujeitos apreendem o esporte no senso comum e atribuem significados ao mesmo, o esporte também permeia os momentos de lazer como mercadoria a ser consumida na lógica do espetáculo televisivo e, porque não dizer, transmidiático (JENKINS, 2009).

O tema da mercadorização do esporte e os processos de apropriação social do mesmo são apresentados por Pires (1998). Estes processos, com ênfase para a mercadorização e espetacularização, constituem um movimento político e econômico que reconhecem o potencial extremamente lucrativo da transformação do esporte em mercadoria. Também implica na necessidade de ofertá-lo socialmente como um verdadeiro espetáculo, mesmo que isso implique em mudanças de regras, adequações à grade de programação de emissoras, adoção de uniformes que valorizem os atributos físicos dos atletas e uma mediação visando a fácil absorção por parte do público, de preferência pautada nos princípios do infotenimento ${ }^{2}$.

Tais características inerentes ao esporte contemporâneo e a apropriação do mesmo pelos meios de comunicação de massa, fizeram com que este modelo de esporte adquirisse um caráter hegemônico em nossa sociedade, a ponto de muitas de suas características serem reproduzidas nos momentos de lazer em geral. Tal fato acarreta em sérias consequências sobre processos de apropriação e vivências do esporte a partir de outras perspectivas, pautada na participação, na ludicidade, na mudança de regras, na valorização dos sujeitos que se movimentam etc. Ou seja, se não houver uma mediação no sentido de questionar e ressignificar tais características hegemônicas do esporte, a chance de limitarmos as possibilidades de consumi-lo e experienciá-lo é muito grande e, portanto, a educação 
escolar e, obviamente, a educação física tem papel fundamental nessa perspectiva.

Sendo assim, é importante salientar que o esporte carrega consigo múltiplas possibilidades de vivências, de aprendizagens e de apropriação social. E é claro que tal gama de possibilidades está ligada às concepções de mundo, de ser humano, de educação, de escola e de esporte daqueles envolvidos no trato pedagógico com este conteúdo, isto é, os professores.

Todavia, tão importante quanto analisar a forma como o esporte é desenvolvido nas escolas a partir da voz dos sujeitos envolvidos, também é fundamental estudar como o mesmo é caracterizado no âmbito das políticas públicas, revelando, assim, os pressupostos subjacentes aos projetos e propostas, seus objetivos, êxitos e limitações, a fim de elencarmos elementos que nos permitam refletir, propor mudanças e qualificar tais ações.

Compreende-se políticas públicas como a "ação das autoridades públicas na sociedade referindo-se àquilo que os governos produzem, para alcançar determinados resultados, através de alguns meios. Nessa concepção, políticas públicas remetem a um conjunto de decisões e a um conjunto de ações para implementar aquelas decisões" (MENICUCCI, 2006, p. 141). Suas características são: a) a existência de um conteúdo; b) um programa que articula ações em torno de eixos específicos; c) uma orientação normativa que expressa finalidades, preferências e valores; d) um fator de coerção uma vez que sua legitimidade é decorrente da autoridade legal; e e) pelo seu alcance, uma vez que todos são afetados pela ação pública (MENY; THOENIG, 1992)³.

Com base neste panorama, a presente investigação se volta para a análise comparativa entre duas políticas públicas do estado de Santa Catarina implementadas entre os anos de 1995 e 2002, que versam sobre o esporte no contexto escolar. São elas respectivamente: a Proposta Curricular de Santa Catarina (PCSC) e o Programa Estadual Esporte Escolar (PEEE).

AProposta Curricular de Santa Catarina é um documento que se apresenta como diretriz pedagógica para o desenvolvimento de todos os componentes curriculares da educação escolar estadual. A primeira versão deste documento foi formulada entre os anos de 1988 e 1991. Este documento então passou a ser revisado e para tal, a Secretaria Estadual de Educação constituiu um grupo de trabalho multidisciplinar que contou com a consultoria 
de professores especialistas de Universidades de todo o país. Após revisão e envio para discussão e avaliação dos professores atuantes na rede estadual de ensino, o mesmo foi publicado no ano de 1995, durante o governo do PMDB ${ }^{4}$.

Estão presentes neste documento os objetivos para educação pública estadual, as concepções subjacentes a uma proposta educacional de cunho crítico e quiçá transformador, dadas as bases teóricas que o fundamentam, e também indicações sobre os conteúdos escolares a serem abordados pelos diferentes componentes curriculares.

Nesta perspectiva, no que tange especificamente à Educação Física, a proposta expõe suas bases e metas, identificando como seus principais temas a corporeidade e o movimento humano. A Educação Física, nesta perspectiva, é pautada a partir da concepção histórico-cultural de educação, que compreende os conhecimentos inerentes às diferentes disciplinas como sendo historicamente produzidos pela humanidade e, consequentemente, se constituem em direito de todos que passam pela escola. Também defende uma concepção de Educação Física voltada para a criticidade e a emancipação humana, que conceba o desenvolvimento dos alunos como seres sociais.

Em relação ao esporte, como conteúdo da Educação Física escolar, os autores da Proposta Curricular de Santa Catarina realizam críticas severas ao esporte de cunho institucionalizado e principalmente acerca da reprodução de seu modelo no âmbito escolar. Defendem que o esporte precisa ser transformado em uma prática educativa, na qual os alunos sejam conscientizados sobre suas relações com outros fenômenos sociais, principalmente de ordem política e econômica. Nesta lógica, o esporte escolar precisa necessariamente romper com elementos como o alto rendimento, a competitividade, a discriminação, a exclusão e assumir uma postura mais condizente com aquilo que se espera da educação escolar: uma educação que emancipe o homem e que contribua para a transformação da sociedade (PROPOSTA CURRICULAR DE SANTA CATARINA, 1995).

Com relação ao Programa Estadual Esporte Escolar, o mesmo foi criado no ano de 2001 no Governo do Partido Progressista (PP) e vigorou durante os anos de 2001 a 2003, quando passou a ser gradativamente substituído pelos Programas Segundo Tempo e Mais Educação. O PEE foi oriundo das ações decorrentes do fracasso olímpico da delegação

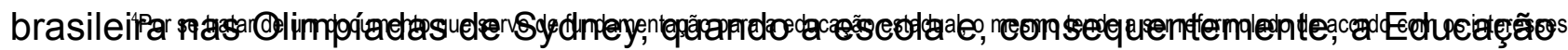
dos partidos políticos que assumem o Governo. No contexto da pesquisa, o documento vigente foi publicado na gestão do PMDB. 
Física escolar foram culpabilizadas pela não formação da base da pirâmide esportiva nacional. Neste contexto também foi criado na esfera federal o Programa Esporte na Escola (Governo FHC) que parece ter inspirado a criação do PEEE em Santa Catarina.

Pode-se afirmar que o mesmo se constitui em uma proposição de oferta da prática esportiva para crianças e adolescentes no contra turno escolar, visando garantir o acesso e permanência da comunidade escolar e integrando a população em situação de risco/ vulnerabilidade social e pessoal. O Programa tem como meta contribuir para a inclusão social, o desenvolvimento integral dos indivíduos participantes e o exercício da cidadania, além de possibilitar a iniciação esportiva.

O documento base do PEEE é dividido em dezoito artigos que tratam especificamente dos recursos financeiros, destacando-se a constituição de orçamento per capta próprio para o programa e subsídios por parte do Programa Nacional Esporte na Escola, das condições para participação dos alunos nas atividades previstas pelo Programa e da constituição de turmas. Também destaca que o profissional responsável pelo desenvolvimento do Programa nas escolas deve ser, preferencialmente, o professor de Educação Física lotado na escola.

Acrescenta-se que consta na portaria que dispõe sobre a criação do programa que os Jogos Escolares de Santa Catarina - JESC, passam a fazer parte do Programa Estadual Esporte Escolar, sendo regulamentado anualmente em documento específico. Em linhas gerais, o programa é apresentado de forma operacional, de maneira que limita ao leitor a identificação de uma base conceitual que sustente seus anseios para o esporte dentro dos muros escolares, fora das aulas de Educação Física em Santa Catarina (SANTA CATARINA, 2002).

Assim, o objetivo da presente investigação foi compreender como o esporte é tratado no âmbito das políticas públicas educacionais no estado de Santa Catarina. Tal meta se volta para a compreensão das concepções de esporte apresentadas nas políticas, as características do trato pedagógico com o esporte em ambos os documentos e a identificação dos pressupostos teóricos inerentes aos autores das duas propostas, ressaltando suas discrepâncias inerentes aos diferentes projetos de governo daquele contexto. 


\section{Procedimentos Metodológicos}

Trata-se de uma pesquisa de análise documental de caráter qualitativo. A escolha pelo caráter qualitativo se deve à pretensão de realizarmos um estudo mais aprofundado, pois segundo Minayo (1994, p. 37) "a abordagem qualitativa aprofunda-se no mundo dos significados das ações e relações humanas, um lado não perceptível e não captável em equações, médias e estatísticas".

Para dar conta dessa abordagem, a execução deste estudo foi dividida em cinco momentos: Fase exploratória; Revisão de literatura; Análise de documentos; Triangulação de dados; e Confronto entre perspectivas.

Dentro da fase exploratória deste estudo (no primeiro momento), realizamos uma leitura inicial da Proposta Curricular de Santa Catarina em seus aspectos gerais, sobre a Educação Física escolar e especificamente no que diz respeito ao esporte escolar. O mesmo foi feito com o intuito de resgatarmos os principais argumentos que fundamentam esta proposta, as características do esporte e o entendimento deste por parte de seus autores. Dentro da mesma perspectiva, também foram estudados os documentos referentes ao Programa Estadual Esporte Escolar. Porém, devido ao seu caráter operacional, procurou-se observar as questões do esporte implícitas nos tópicos que compunham este documento. Nesta fase puderam ser identificadas as posições coincidentes e possíveis contradições, que foram destacadas para posterior análise. Também nesta fase foram definidas as categorias de análise (a) cultura escolar de esporte e b) esporte e inclusão social, a serem utilizadas na triangulação de dados.

No que diz respeito à categoria "cultura escolar de esporte", ela surgiu a partir da necessidade de discutirmos o esporte escolar com base nas perspectivas do esporte na escola e do esporte da escola, como apresentado por Bracht (1992) e Vago (1996). Assim, visou-se compreender como diferentes expectativas com relação ao esporte em uma mesma instituição poderiam impactar a tensão permanente que alicerça a cultura escolar de esporte.

Acerca da categoria "esporte e inclusão social", a mesma é oriunda da necessidade de 
analisarmos um discurso muito comumente difundido em nossa sociedade de que o esporte é tido como uma ferramenta para se alcançar diversos fins sociais como saúde, cidadania, inclusão social, combate às drogas, combate à exploração do trabalho infantil, etc. Ou seja, como esse é um aspecto presente em um dos documentos analisados, nos interessou confrontar os objetivos das duas propostas e suas características a fim de proporcionar uma visão crítica sobre as expectativas com relação ao esporte.

Sequencialmente foi realizada uma revisão de literatura com base nas principais obras (livros e artigos) de autores brasileiros que se debruçaram sobre o tema do esporte no âmbito da escola e da Educação Física escolar. É importante ressaltar que durante toda a realização do estudo, foi feita a devida revisão dessa literatura para dar mais embasamento à pesquisa.

A análise documental foi iniciada com uma apresentação, em linhas gerais, da Proposta Curricular de Santa Catarina e do Programa Estadual Esporte Escolar, expondo assim, suas principais características e elencando elementos para a análise. E, com base nos dados coletados nos documentos, foi realizada a triangulação de dados. Esta consistiu numa comparação entre os pressupostos e argumentos defendidos pelos autores dos dois documentos em questão e os elementos constituintes das categorias de análise. Dessa forma, realizamos um diálogo entre o que é apresentado nos documentos e, a partir dos elementos presentes nas categorias de análise puderam ser explicitadas as diferenças e contradições entre os documentos com relação ao esporte em âmbito escolar.

\section{Cultura Escolar de Esporte}

Por muito tempo acreditou-se que a escola se constituía em uma instituição na qual os indivíduos deveriam ser formados através da transmissão de conhecimentos que eram elaborados fora da mesma, sem uma conexão viva com a realidade escolar. A respeito disso, Chervel ${ }^{5}$ (1990, p.182) nos fala que "a concepção de escola como puro e simples agente de transmissão de saberes elaborados fora dela está na origem da ideia, muito amplamente partilhada no mundo das ciências humanas e entre o grande público, segundo a qual ela é, por excelência, o lugar do conservadorismo, da inércia, da rotina". 
Posicionando-se contra tal pressuposto, Vago (2003) afirma que a sociedade produz a escola tanto quanto é também por ela produzida, estabelecendo uma complexa tensão que engloba as expectativas com relação ao currículo escolar e também real forma como a efetivação do mesmo ocorre. Dentro desta lógica, percebe-se a importância de se superar a percepção da escola como mera reprodutora linear e mecânica de tudo o que se lhe impõem de fora para dentro. Mesmo porque "a escola não é uma ilha na sociedade. Não está totalmente determinada por ela, mas também não está livre dela" (OLIVEIRA, 1999/2000, p.20). Assim, acreditamos ser fundamental compreender e investigar a escola como lugar de organização e produção de uma cultura própria, específica — ou seja, uma cultura escolar.

De acordo com Vago (2003, p. 06), os elementos centrais na constituição de uma cultura escolar são: "um saber jurídico e político produzido específica e especialmente para a escola (legislação do ensino, mapeamentos estatísticos, por exemplo); uma organização física do espaço escolar (prédios, mobiliário); os materiais escolares; a divulgação de novos métodos de ensino e a redefinição de currículos, disciplinas e tempos escolares". Pode-se acrescentar ainda as linguagens ou modos de comunicação.

Cultura escolar de esporte, por sua vez, pode ser determinada como uma prática escolar de esporte que, para além da reprodução das características do esporte de alto rendimento, engloba aspectos como a ludicidade, a criatividade, o brincar, a invenção e a alegria - "usos e significados ambíguos, estruturados em uma tessitura de dominação, alienação, prazer, ludicidade, emancipação..." (FARIA, 2001, p.12).

A cultura escolar de esporte é estruturada a partir do confronto entre as características do esporte de cunho institucionalizado, como a exclusão, competição, hierarquia e rivalidade; e elementos próprios das relações estabelecidas entre os sujeitos da escola, como a ludicidade, a criatividade, o brincar, a invenção, a alegria, a solidariedade e a cooperação. Esta é uma tessitura complexa do cotidiano escolar que resulta em significações e usos diversos de um mesmo elemento da cultura corporal de movimentos. Desse emaranhado de características que compõe a cultura escolar de esporte, percebe-se claramente a ambiguidade e a contradição entre as mesmas - fato esse que explicita a tensão entre o esporte na escola e o esporte da escola. 
O "Esporte da escola" pode ser caracterizado como uma prática esportiva em âmbito escolar como manifestação de resistência às características da instituição esportiva (treinamento, seleção de talentos, especialização precoce, etc.). É dotado de fins pedagógicos, e os indivíduos podem apropriar-se do mesmo de forma lúdica, criativa e prazerosa. O "Esporte na escola" constitui-se no esporte que segue incondicionalmente os padrões impostos pelo esporte institucionalizado, valorizado pela mídia, com fins no alto rendimento e na descoberta de talentos esportivos (VAGO, 1996). Estas duas perspectivas para o esporte em âmbito escolar estabelecem uma relação de tensão permanente que resulta no que chamamos de cultura escolar de esporte.

\section{Esporte e Inclusão Social}

A inclusão social tem sido utilizada como bandeira em diferentes políticas e projetos, sobretudo na área social, seja na esfera estatal, no âmbito da responsabilidade social, da iniciativa privada e também nas ações do terceiro setor. O esporte geralmente compõe as ações na perspectiva, sobretudo quando envolve a participação de crianças e jovens em situação de vulnerabilidade e risco social. Dessa maneira, o termo "esporte social" surgiu com o fim de abarcar uma série de demandas sociais para as quais o esporte poderia contribuir de maneira decisiva.

A concepção do esporte como uma saída para o quadro de vulnerabilidade social no qual estão inseridos milhares de crianças e jovens em nossa sociedade acabou por atribuir ao mesmo uma série de tarefas sociais. O esporte, nesta concepção funcionalista, e por que não dizer "salvacionista", passou a poder tudo: ele é capaz de evitar que as crianças e jovens se envolvam com as drogas e com a criminalidade em geral, pode acabar com a exploração do trabalho infantil, é um passaporte para a cidadania, pode garantir uma vida melhor aos mesmos por meio da ascensão social etc.

Essa perspectiva de esporte social é reforçada cotidianamente no senso comum tomando como base o exemplo de diversos ex-atletas que "penduraram as chuteiras" e passaram a "suar a camisa" em nome da transformação da realidade de crianças e jovens "carentes" por meio de projetos esportivos. 
Todavia, devemos chamar a atenção para o fato de que tais projetos, que adotam o "esporte social" como bandeira para a transformação social, associam suas ações à visada transformação social de uma forma linear, sem levar em consideração uma série de questões de ordem conceitual e logicamente de ordem social. A abordagem que reveste o esporte na presente perspectiva busca no esporte um tipo de "saída fácil" para os principais problemas sociais que afligem, principalmente, a infância e a juventude.

Tomando como base esta lógica utilitarista, constatamos que o esporte jamais foi considerado como um fim em si mesmo, e esta preocupação também ficou a parte na questão da inclusão social. Pensa-se em uma inclusão na qual o esporte constitui-se como veículo para muitas coisas; em contrapartida, não é pensado um viés pelo qual as pessoas seriam incluídas no esporte em si. Ou seja, não se propõe uma possibilidade de experiência com o esporte na qual as crianças e jovens teriam acesso a elementos que as possibilitasse apreender criticamente o fenômeno esportivo, o vivenciassem de uma forma diferenciada e se apropriassem do mesmo ao longo de toda a vida em seus momentos de lazer.

A partir desse emaranhado de informações, aflora a seguinte questão: por que a inclusão social não pode ocorrer através do esporte, mas também no e para o esporte? Em outras palavras, por que não contemplar a democratização do conhecimento esporte como uma forma de inclusão social? Será que o mesmo só é válido para se alcançar fins em uma perspectiva salvacionista?

Logicamente, quando as políticas públicas nos dizem que o esporte serve para tirar as crianças da rua, amenizar o problema das drogas, beneficiar a saúde de seus praticantes, obtém um maior retorno (ou interesse) por parte da grande massa da população. Isto se deve ao fato de que, o apelo aos problemas sociais cotidianos chama a atenção das pessoas, e o esporte, nesta perspectiva, acaba rotulado como uma das possíveis soluções para amenizar tais problemas.

Entendido como manifestação da cultura corporal de movimentos que deve ser praticada, assistida, compreendida, criticada e transformada, o esporte acaba colocado em segundo plano. Todavia, de acordo com Kunz (1998, p. 08), 
construção social, sendo sua inserção procedida na condição tanto de ator quanto - e principalmente - de autor da sua própria cultura [corporal] de movimentos/ esportiva.

Para tal, é importante se ressignificar esta proposta inclusiva que apenas mascara os problemas sociais inerentes ao modo de produção no qual estamos inseridos e não os ataca frontalmente com ações efetivas a longo prazo, que extrapolam em muito as contribuições do esporte social. É preciso apostar em outra compreensão do esporte, como direito social a ser usufruído por todos e, nessa mesma lógica, estruturado a partir de uma perspectiva crítica que possibilite uma apropriação mais voltada para os interesses de uma vivência esportiva dotada de sentido para os sujeitos e pautada na ludicidade do que meramente como uma das bases para o consumo no mercado do esporte.

\section{A Abordagem do Esporte nos Documentos em Relação à Categoria "Cultura Escolar de Esporte"}

Na Proposta Curricular de Santa Catarina, por seus autores trabalharem com a concepção histórico-cultural, é dada ênfase ao fato do aluno adentrar ao meio escolar dotado de conhecimentos do seu cotidiano e, que, portanto, a escola deverá estabelecer um diálogo entre tais saberes e a transmissão/produção do saber escolar. A proposta em questão entende que o aluno chega à escola com saberes do seu cotidiano; ele já possui conhecimentos. Assim, a escola deve assumir o papel de mediadora do diálogo entre estes conhecimentos e o conhecimento transmitido e produzido na escola.

A intenção, dentro de uma prática pedagógica, não é negar tais conhecimentos, porém não se pretende reforçá-los como uma prática escolar de maneira acrítica. A escola deve assumir o papel de mediação entre estes conhecimentos e o seu projeto político pedagógico compromissado com a utopia de uma sociedade mais justa, de maneira a criar um espaço de permanente discussão, esclarecimento e apropriação crítica do fenômeno esportivo.

Dentro desta perspectiva, é possível apresentarmos um paralelo entre tal pressuposto e o que se definiu como Cultura Escolar de Esporte. Isto porque se encontra explícita a possibilidade de se criar a citada tensão permanente entre os conhecimentos advindos de fora da escola (no caso do esporte, os conhecimentos transmitidos pela mídia) e a produção 
de um saber escolar (leia-se trato pedagógico crítico do esporte).

Outro ponto que é pertinente citar relaciona-se ao fato de que neste caso a tensão tende a se voltar predominantemente para o esporte da escola, sobretudo em virtude da perspectiva de transformação das regras do esporte, proporcionando ao educando uma transposição deste conhecimento ambíguo para além dos muros escolares, na busca de uma possível mudança na sua apropriação fora da escola.

Na Proposta Curricular de Santa Catarina são apresentadas diversas críticas ao esporte de cunho institucionalizado e, com base nisso defendem que o esporte de alto rendimento não deve se constituir no objeto da Educação Física escolar, ao menos que sirva como objeto de reflexão sobre a sua presença no mundo contemporâneo/cotidiano da vida das pessoas. Daí a necessidade de se propor uma perspectiva de esporte que supere a tendência do alto rendimento e que se volte para uma transformação do mesmo, de maneira a se criar um esporte verdadeiramente da escola, um esporte pedagogicamente transformado.

Em síntese, propõe-se uma perspectiva de esporte na qual as pessoas possam ter a chance não somente de praticá-lo, mas de poderem criticá-lo frente a sua oferta pelos meios de comunicação de massa, compreendê-lo enquanto fenômeno cultural de suma importância para a reprodução da estrutura de classes na sociedade capitalista (BRACHT, 2003), e, sobretudo, terem a perspectiva de uma possível transformação do esporte, a fim de lhe atribuir um sentido mais humano em suas vidas.

Ainda explorando a categoria Cultura Escolar de Esporte, vejamos agora o que nos apresenta o Programa Estadual Esporte Escolar.

No Programa podemos perceber claramente um número de contradições que acaba pondo em xeque o seu real objetivo, qual seja a inclusão de grupos sociais em situação de risco social e pessoal. Uma das maiores contradições nos remete a um trato com o esporte de alto rendimento em âmbito escolar. Isso nos leva a pensar que a tensão permanente que deveria ser estabelecida entre o esporte da e na escola pode ser influenciada por uma

Exemplo disso é a portaria que dispõe sobre a criação do Programa na qual consta o seguinte: "os suposta cooptação da instituição escolar pela instituição esportiva. jogos escolares de Santa Catarina - JESC, passam a fazer parte do Programa Estadual Esporte Escolar, sendo regulamentado anualmente em documento específico" (SANTA CATARINA, 2002, p. 02). Assim, é possível indagar que, uma vez presente nos eventos do Programa, os Jogos Escolares não poderiam resultar numa reformulação dos objetivos do mesmo durante a sua prática no cotidiano escolar? 
Em outras palavras, a inclusão social não poderia ser facilmente substituída pelo alto rendimento e pelas características que foram anteriormente negadas? Em vista disso, pode-se imaginar que as manifestações lúdicas ou de resistência à opressão do esporte de alto rendimento poderiam ser gradativamente alteradas e, ao final das contas, as pessoas acabariam egressando da escola com a mesma visão de esporte com a qual ingressaram.

Não há dúvidas de que, embora tenha se tentado esconder, o objetivo maior do projeto é conceber a escola como o local onde o talento esportivo será descoberto, ou ainda numa fábrica de consumidores para o mercado do esporte de alto rendimento. Essa é uma discussão recorrente na área, haja vista a responsabilidade que geralmente é atribuída à escola pela formação de atletas após desempenhos insatisfatórios nos Jogos Olímpicos.

\section{A Abordagem do Esporte nos Documentos em Relação à Categoria "Esporte e Inclusão Social"}

Na Proposta Curricular de Santa Catarina o esporte, por se tratar de uma construção social, é entendido como um direito de todos que passam pela escola. A partir disso e, tomando como pressuposto uma socialização do esporte como agente de transformação, vemos que se almeja outra compreensão do esporte. Através dessa nova compreensão espera-se que as pessoas se afeiçoem à prática esportiva e possam lhe atribuir um real sentido em suas vidas.

É importante frisar que uma nova compreensão de esporte inclui além da simples prática, um olhar dotado de certa complexidade sobre o fenômeno esportivo e como grande meta a transformação do esporte pelos sujeitos, de maneira que estes se constituam atores/ autores do seu esporte.

$\mathrm{Na}$ Proposta afirma-se que o Esporte deve ser visto como um meio para se alcançar objetivos maiores. Não pretendemos repetir a crítica a esta afirmação, mas salientar a importância destas palavras no que se refere à presença do esporte de alto rendimento nas aulas de Educação Física e o seu papel na exclusão dos sujeitos no âmbito da cultura corporal de movimentos.

Em outro momento na Proposta afirma-se que é de suma importância transformar o esporte em uma prática educativa, conscientizando os alunos das relações que existem 
entre o esporte e os fenômenos sociais. Isso só tende a ressaltar a relevância de um trato com o conhecimento esporte que extrapole os limites da prática esportiva, caminhando para uma suposta inclusão social no mesmo, uma vez que se torna possível compreender o esporte, tem-se a perspectiva de criticá-lo e quiçá transformá-lo.

Tomando ainda como referencial a categoria Esporte e Inclusão Social, analisaremos neste momento o Projeto Estadual Esporte Escolar.

É importante deixar claro desde já que no Programa analisado neste instante apresentase um objetivo que se refere a uma perspectiva de inclusão social. Entretanto, numa leitura mais atenta percebe-se que seu maior objetivo ainda é a promoção do esporte de alto rendimento em âmbito escolar.

Não foi possível encontrar nenhuma característica que viesse ao encontro da perspectiva de Esporte e Inclusão Social exposta em nossa base teórica. Isto se deve principalmente à máscara que foi dada ao Programa. Não se percebe nenhuma concepção teórica que fundamente o trato com o esporte pretendido no Programa, as contradições são gritantes no que se refere até mesmo a uma Inclusão Social de caráter funcionalista e a perspectiva para o esporte é a busca do alto rendimento.

Por exemplo, dentro do PEEE incluem-se as seguintes condições para a participação dos alunos: ser regularmente matriculado na escola admitida no Programa, não ser dispensado da prática da Educação Física escolar, não estar inscrito em nenhuma federação, ter aproveitamento escolar suficiente e frequência regular, pois três faltas consecutivas ou cinco alternadas bastam para desligar o aluno do Programa.

Bem, indubitavelmente estão expressas acima as maiores contradições do Programa no que se refere à Inclusão social, uma vez que são impostas tantas condições/restrições para a participação dos "excluídos" socialmente. Mais gritante a contradição no que tange ao aproveitamento escolar e à frequência exigida, pois acreditamos que devido às condições do cotidiano de suas vidas, essas pessoas possuam limitações (alimentação, cuidados, renda familiar, carinho, violência urbana, etc.) que tendem a refletir nas notas e, sobretudo, em sua assiduidade às aulas.

Outra contradição está ligada ao fato de que "as aulas devem ser desenvolvidas nos dias úteis da semana, somente em casos excepcionais serão permitidas aos sábados" 
(SANTA CATARINA, 2002, p.04). Sobre isso, é imprescindível mencionar aqui alguns questionamentos de Pires (2002, p.06):

será que aos finais de semana estes alunos ficam livres da situação de risco pessoal e social que justifica sua participação no Programa? E mais: se a intenção é a inclusão social, não seria desejável que se buscasse a integração familiar - cuja falta pode ser, muitas vezes, a causa mais visível da situação de risco através do esporte escolar, o que parece mais factível nos finais de semana? Além disso, sabe-se que adolescentes e jovens em situação de risco têm enormes dificuldades em se submeterem a normas muito rígidas; então, será que faz sentido a existência de tantas restrições, punições e 'castigos' aos alunos participantes, algumas implicando o seu afastamento definitivo do programa?

Podemos acrescentar ainda que não se propõe o acesso às diversas modalidades e conhecimentos sobre o esporte, ficando iminente a tendência à especialização esportiva dos sujeitos. Com base nesses argumentos podemos afirmar que o Programa Estadual Esporte Escolar não pode ser caracterizado como uma política pública voltada para a inclusão social em relação ao esporte.

\section{Considerações Finais}

Como o esporte é tratado dentro do âmbito das políticas públicas educacionais no estado de Santa Catarina? Esta foi a pergunta que nos trouxe até aqui. E qual a resposta? Com indiferença, falta de sensibilidade, partidarismo, equívocos teóricos, ausência de diálogo, com falta de respeito aos atores/autores da escola e com a sociedade, com características bastante específicas de acordo com as equipes de governo constituídas, desconsiderando as proposições anteriores.

A partir da discussão que empreendemos nas linhas que antecederam estes escritos finais, tomando como base as políticas públicas para o esporte escolar em Santa Catarina naquele contexto de mudança de gestão governamental, foi possível perceber a possibilidade da escola se tornar um ponto de (des)encontro entre as políticas públicas voltadas para o esporte em âmbito escolar.

De forma hipotética, poderíamos pensar num professor de Educação Física com duas faces muito distintas: durante as aulas de Educação Física estaria comprometido com um trato com o conhecimento esporte, voltado para a sua reconstrução e a reapropriação crítica 
do mesmo. Num passe de mágica seria um professor envolvido pela farsa da inclusão social "através" do esporte, voltando seus esforços para a formação de novos atletas e consumidores para o esporte.

Se temos uma proposta consolidada com uma fundamentação teórica consistente e compromissada com a mudança do esporte, da escola, da sociedade, como é possível dar tamanho passo para trás e se propor um programa no qual a inclusão social é o carro chefe, mas que na verdade faz emergir o conservadorismo do esporte de alto rendimento na escola?

De acordo com o que foi constatado com relação à categoria Cultura escolar de esporte, tornam-se gritantes as diferenças de perspectiva de esporte a serem desenvolvidas no âmbito de uma mesma instituição. No caso da Proposta Curricular de Santa Catarina, as concepções subjacentes ao trato pedagógico do esporte se aproximam do que foi definido como esporte da escola, isto é, um esporte pedagogicamente transformado. Por outro lado, dadas às características do Programa Estadual Esporte Escolar, é perceptível a reprodução de um conjunto de práticas inerentes ao esporte de cunho institucionalizado em âmbito escolar, ou seja, aquele definido como esporte na escola.

Em relação à categoria Esporte e inclusão social as diferenças também se estabelecem compararmos os dois documentos: a Proposta Curricular de Santa Catarina, ao defender o esporte como um conjunto de conhecimentos ao qual o aluno tem direito quando ingressa no ambiente escolar, propõe que ser incluído no esporte é incorporá-lo à sua vida cotidiana, de maneira que o mesmo possa usufruí-lo inclusive para além da sua vida escolar. Já, no que tange ao Programa Estadual Esporte Escolar, o mesmo defende a inclusão social como princípio fundante, principalmente ligada às populações em risco pessoal/social. Todavia, acaba por revelar em suas entrelinhas concepções de esporte mais próximas de uma perspectiva de alto rendimento e competição. Concepções estas que estão muito distantes de uma possível contribuição para a inclusão social, inclusive numa perspectiva funcionalista.

Como já ressaltamos em momento anterior, esta pesquisa não tem a pretensão de solucionar o problema do embate entre os dois documentos para oesporte na/da escolaem Santa Catarina. Entretanto, acreditamos ser importante apontar uma possibilidade de se propor um encontro entre ambos. 
A possibilidade que defendemos pode ser entendida como uma apropriação dos conhecimentos referentes ao esporte dentro dos muros escolares para uma reapropriação de forma crítica do fenômeno esportivo no lazer. Ou como nos diz Oliveira (2001, p. 114) "o aprendizado para o consumo crítico do fenômeno esportivo".

Dessa forma, faz-se a opção por práticas educativas que resultem em constante exposição dos alunos e alunas a experiências lúdicas, de modo que todo o processo ensinoaprendizagem se dê através de valores como espontaneidade, criatividade e descoberta. Vale ressaltar que o trato com o esporte, nesta perspectiva, carece de atividades acompanhadas de devida reflexão, constituindo-se em uma práxis pedagógica envolvida com vivências e reflexões sobre a cultura corporal de movimento. Será que aos finais de semana estes alunos ficam livres da situação de risco pessoal e social que justifica sua participação no Programa? E mais: se a intenção é a inclusão social, não seria desejável que se buscasse a integração familiar - cuja falta pode ser, muitas vezes, a causa mais visível da situação de risco - através do esporte escolar, o que parece mais factível nos finais de semana? Além disso, sabe-se que adolescentes e jovens em situação de risco têm enormes dificuldades em se submeterem a normas muito rígidas; então, será que faz sentido a existência de tantas restrições, punições e 'castigos' aos alunos participantes, algumas implicando o seu afastamento definitivo do programa?

Almejamos uma aula de Educação Física capaz de proporcionar aos sujeitos uma formação cultural crítica e divertida, de maneira que seja possível se ensinar o esporte às nossas crianças de tal forma que as mesmas possam crescer, se desenvolver e se tornar adultas com ele, e quando isto acontecer, quando se tornarem adultas, possam praticar esportes, movimentos e jogos como crianças" (KUNZ, 2001-b, p.56).

Esta é, na nossa visão a maneira através da qual o esporte pode ser modificado dentro do ambiente escolar e assim retornar à sociedade de modo a também, neste cenário mais amplo, provocar tensão e podermos todos brincar de esporte. 


\section{Referências}

BRACHT, V. Educação Física e aprendizagem social. Porto Alegre: Magister, 1992.

Sociologia crítica do esporte: uma introdução. 2a Edição. ljuí: UNIJUI, 2003.

FARIA, E. L. O esporte na cultura escolar: usos e significados. Belo Horizonte, 2001. $162 \mathrm{f}$. Dissertação (Mestrado em Educação) Faculdade de Educação, Universidade Federal de Minas Gerais.

GOMES, I. M. M. 0 embaralhamento de fronteiras entre informação e entretenimento e a consideração do jornalismo como processo cultural e histórico. In: DUARTE, E. B.; CASTRO, M. L. D. (orgs.). Em torno das mídias: práticas e ambiências. Porto Alegre: Sulina, 2008.

JENKINS, H. Cultura da convergência. $2^{\mathrm{a}}$ ed. São Paulo: Aleph, 2009.

KUNZ, E. Educação Física escolar: seu desenvolvimento, problemas e propostas. Santa Maria: Seminário brasileiro de Pedagogia do Esporte, Anais, p. 114-119, set. 1998.

. Transformação didático-pedagógica do esporte. $4^{\mathrm{a}}$ Ed. ljuí: UNIJUII, 2001(b).

MENICUCCI, T. Políticas públicas de lazer: questões analíticas e desafíos políticos. In: ISAYAMA, H.; LINHALES, M. A. (orgs.) Sobre lazer e política: maneiras de ver, maneiras de fazer. Belo Horizonte: editora UFMG, 2006. P.136-164.

MINAYO, M. C. de S. (org.) et al. Pesquisa social: teoria, método e criatividade. Petrópolis: Vozes, 1994.

OLIVEIRA, S. A. de. Escola e esporte: campos para ocupar, resistir e produzir. Pensar a prática. Vol. 3. Jun./Jul., p. 19-35, 1999/2000. 
Reinventando o esporte: possibilidades da prática pedagógica. Campinas: Autores Associados, 2001.

PIRES, G. de L. Breve introdução ao estudo dos processos de apropriação social do fenômeno esporte. In: Revista da Educação Física. Maringá: nº 9, p. 25 - 34, 1998.

A Escola, a Educação Física e as Políticas Públicas: quais são os projetos para o esporte escolar? Florianópolis, 2002. (mimeo)

PROPOSTA CURRICULAR DE SANTA CATARINA. Educação infantil, ensino fundamental e médio: disciplinas curriculares. Florianópolis: COGEN, 1998.

SANTA CATARINA. Secretaria de Estado da Educação e do Desporto. Programa Estadual Esporte Escolar. Disponível em $<w w w . s e d . r c t-s c . b r / d i r e t r-p e e>$. Acesso em 28/11/2002.

VAGO, T. M. O "esporte da escola" e o "esporte na escola": da negação radical para uma relação de tensão permanente - um diálogo com Valter Bracht. In: Revista Movimento. Ano 3. nº 5. Porto Alegre, 1996, pp $04-17$.

Cultura Escolar e/de Educação Física: tateando caminhos para a intervenção e a pesquisa. Belo Horizonte, 2003. (mimeo) 


\section{THE SPORT OF/IN SCHOOL IN THE PUBLIC POLICIES AT SANTA CATARINA}

Abstract: This research is result from a documental analysis about the public politics to school sport in Santa Catarina. Especificly the curricular propose of Santa Catarina and the state program school sport. From the analysis we see that the contradictions between the documents are huge, establishing a conflict between them. So, we will show how can be different the politics to the school sport in and out of the Physical Education classes and the consequences of the work with the sport in perspectives apparently so distinct in the same institution.

Keywords: sport, school, public policies.

\section{EL DEPORTE LA/EN ESCUELA EN LAS POLÍTICAS PÚBLICAS EN SANTA CATARINA}

Resumen: Esta investigación es el resultado de un análisis documental sobre las políticas públicas para el deporte escolar en "Santa Catarina". En concreto, la Propuesta Curricular de "Santa Catarina" y el "Programa Estadual Esporte Escolar". A partir del análisis vemos que las contradicciones entre los documentos son enormes, se establece un conflicto entre los mismos. Así, mostraremos cuanto pueden ser diferentes las políticas para el deporte escolar dentro y fuera de las clases de Educación Física y las consecuencias del trato con el deporte en perspectivas aparentemente tan distintas en una misma institución.

Palabras clave: deporte, escuela, políticas públicas. 